\section{Wie SARS-CoV-2 die Wirtszellen verändert}

Bojkova D et al. Proteomics of SARS-CoV-2infected host cells reveals therapy targets. Nature 2020. doi:10.1038/s41586-020-2332$7(2020)$

Die Therapie von COVID-19 besteht derzeit aus der supportiven und symptomatischen Versorgung. Die Forschergruppe am virologischen Institut der Universität Frankfurt identifizierte zelluläre Signalwege, die von einer Infektion mit SARS-CoV-2 beeinflusst werden. Daraus ergaben sich vielsprechende Ansätze für eine kausale Behandlung.

Die Wissenschaftler nutzten eine neue Methode (Multiplexed enhanced Protein Dynamics [mePROD]), mit der modulierte Translationsleistungen und Proteomveränderungen im Zeitverlauf erfasst werden. Dafür stand ein Zellkulturmodell mit einer Darmzelllinie zur Verfügung (Caco-2-Zellen).

Nach der Infektion mit SARS-CoV-2 nahm die Virus-DNA schnell zu. Die Färbung viraler Nukleoproteine ergab eine Produktion von Virusproteinen in den meisten Wirtszellen. Für ein zeitliches Profil der SARS-CoV-2-Infektion erfolgte eine 2- bis 24-stündige Kultivierung der infizierten Zellen. Die quantifizierten Veränderungen der Translatome (2715 Proteine) und Proteome (6382 Proteine) wurden mit nicht infizierten Zellen verglichen. Die meisten RNA-Viren reduzieren den Proteinstoffwechsel ihrer Wirtszelle zugunsten der eigenen Proteinproduktion. Bei SARS-CoV-2 nahmen die Translationsraten der Wirtszelle und des Virus hingegen zu. Bei 244 Proteinen bestand eine extensive Anreicherung. Außerdem stiegen Splicing-Mechanismen und die Basensynthese deutlich an. Daraus entstand die Hypothese einer Wirksamkeit von Translationsinhibitoren. Cycloheximid und Emetin reduzierten in nicht toxischen Konzentrationen signifikant die SARS-CoV-2-Replikation.

Frühzeitig postinfektiös bestanden nur geringfügige Veränderungen des Wirtsproteoms. 24 Stunden nach der Infektion zeigte sich eine ausgeprägte Modulation. Der Cholesterinstoffwechsel war herunterreguliert, die Kohlehydrat- und Proteinsynthese angekurbelt. Die Zugabe von Pladienolid, einem Splicing-Inhibitor, verhinderte die Virusvermehrung. Die Glykolysehemmung mit dem Hexokinaseinhibitor 2-Deoxy-D-Glukose führte ebenfalls zu einer Beeinträchtigung der Virusreplikation. Beide Substanzen wurden als mögliche therapeutische Wirkstoffe bei einer SARS-CoV-2-Infektion bezeichnet.

Für die Identifizierung möglicher weiterer Replikationsinhibitoren führten die Forscher eine Genontologie mit 459 Proteinen durch. Die Virusvermehrung hing von diversen untergeordneten Nukleinsäuresignalwegen ab. Ribavirin hemmt die Inosinmonophosphat-Dehydrogenase, die die Synthese von Guanosin-Nukleotiden eindämmt und bei den Coronaviren HCoV-43, CoV-NL63 und MERS-CoV, nicht aber bei SARS-CoV wirksam war. Möglicherweise stellt die Substanz aber bei COVID-19 eine therapeutische Option dar. p97 ist eine Schlüsselkomponente des Proteingleichgewichts auf molekularer Ebene. Der bei der Influenza A und B wirksame p97-Inhibitor NMS-873 verhinderte in niedrigen, nanomolaren Konzentrationen die Replikation von SARS-CoV-2.

\section{FAZIT}

Die Studie wies postinfektiöse Stoffwechselveränderungen in den Virusund den Wirtszellen nach. Der Translationsinhibition durch das Virus stand eine kompensatorisch angekurbelte Translationsmaschinerie der Wirtszelle gegenüber, so die Autoren. Sie identifizierten mehrere Substanzen, die im Modell die Virusreplikation verhinderten und in klinischen Settings untersucht werden sollten.

Dr. med. Susanne Krome, Melle 